\title{
GESTÃO DE RESÍDUOS SÓLIDOS DE SERVIÇOS DE SAÚDE
}

\author{
SOLID WASTE MANAGEMENT OF NATIONAL HEALTH SERVICES
}

\author{
Daniel de Sousa Melo Júnior ${ }^{1}$ \\ Eduarda Miranda Leal Souza ${ }^{2}$ \\ Eliane Oliveira Soares ${ }^{3}$ \\ João Divino dos Santos Silva ${ }^{4}$
}

\begin{abstract}
RESUMO: Atualmente, no Brasil há vários tipos de descartes dos resíduos sólidos de serviços saúde. O conhecimento de resíduos é importante, tendo em vista as preocupações com seu descarte, por ser um risco à saúde humana e ao meio ambiente. Pois se não houver compromisso adequado com a eficiência no procedimento técnico e no manejo dos diferentes tipos de lixo gerados, estaremos comprometendo o ambiente ecologicamente. Segundo a Resolução da Diretoria Colegiada (RDC), no 222 de 28 de março de 2018, na seção III do artigo terceiro no inciso XXVII, gerenciamento dos resíduos de serviços de saúde, conjunto de procedimentos de gestão, planejados e com a implementação a partir de bases científicas, técnicas, normativas e legais, com o objetivo de minimizar a geração de resíduos e proporcionar um encaminhamento seguro, de forma eficiente, visando à proteção dos trabalhadores e a preservação da saúde pública, dos recursos naturais e do meio ambiente, representando avanço na busca da regulamentação e das boas práticas no tratamento de Resíduos de Serviços de Saúde, em direção ao desenvolvimento sustentável. Contudo, as dificuldades na fiscalização, no cumprimento da legislação e em possíveis punições aos estabelecimentos que não se ajustarem à RDC vigente perduram como desafios importantes para os órgãos fiscalizadores. Abordar as leis e cumprimentos delas mediante a política nacional de resíduos sólidos. Examinar a gestão dos Resíduos de Serviços de Saúde (RSS) é um desafio, pois á falta desse plano de gerenciamento dos resíduos, ocasionando assim um erro no processo do manejo, falha do abrigo externo, equívocos nas decisões principalmente quanto à responsabilidade técnica.
\end{abstract}

Palavras-chave: Sustentabilidade Ambiental. Gerenciamento de serviços de saúde. Destinação dos Resíduos sólidos de serviço saúde.

ABSTRACT: Currently, in Brazil there are several types of solid waste disposal from health services. The knowledge of waste is important, in view of the concerns with its

\footnotetext{
IGraduanda em Engenharia Civil, Faculdade Aldete Maria Alves/FAMA, Iturama/MG. E-mail: elianesoare34@gmail.com

${ }^{2}$ Graduanda em Engenharia Civil, Faculdade Aldete Maria Alves/FAMA, Iturama/MG. E-mail: elianesoare34@gmail.com

${ }^{3}$ Graduanda em Engenharia Civil, Faculdade Aldete Maria Alves/FAMA, Iturama/MG. E-mail: eduardaleal9416@gmail.com

${ }^{4}$ Mestre em Ciências Ambientais (Universidade Brasil), Especialista em Engenharia Sanitária, Graduado em Engenharia Civil, Coordenador e Docente do curso de Engenharia Civil da Faculdade Aldete Maria Alves/FAMA, Iturama/MG. E-mail: professorjd@outlook.com
} 
disposal, as it is a risk to human health and the environment. Because if there is no adequate commitment to efficiency in the technical procedure and in the handling of the different types of waste generated, we will be compromising the environment ecologically. According to the Resolution of the Collegiate Board (RDC), no 222 of March 28, 2018, in section III of the third article in item XXVII, management of health service waste, set of management procedures, planned and with the implementation from scientific, technical, normative and legal bases, with the objective of minimizing the generation of waste and providing a safe, efficient way, aiming at the protection of workers and the preservation of public health, natural resources and the environment, representing progress in the search for regulation and good practices in the treatment of Health Services Waste, towards sustainable development. However, difficulties in inspection, compliance with legislation and possible penalties for establishments that do not conform to the current DRC remain as important challenges for the inspection bodies. Address their laws and compliance with the national solid waste policy. Examining the management of Health Services Residues (RSS) is a challenge, since the lack of this waste management plan, thus causing an error in the management process, failure of the external shelter, mistakes in decisions, especially regarding technical responsibility.

Keywords: Environmental Sustainability. Health service management. Disposal of solid health service waste.

\section{INTRODUÇÃO}

A história das políticas ambientais teve início através do surgimento das mais variadas leis, normas técnicas e outras regulamentações, para preservação ambiental e um melhor aproveitamento dos recursos naturais, através dos poderes públicos, a iniciativa privada e a sociedade civil.

A política nacional do meio ambiente teve suas primeiras tentativas por parte das instituições governamentais, a fim de ser um alento para a preservação do meio ambiente, por variados órgãos em todas as esferas: municipal, estadual e federal, embora as ações não coordenadas ocasionassem conflitos de poder. (BARROS,2012)

A Lei no 6938, de 31 de agosto de 1981, definiu o que é meio ambiente. Portanto foi através desta lei que se criou o sistema nacional de meio ambiente (SISNAMA).

Já a Política Nacional dos Resíduos Sólidos foi normatizada pela lei n. 12.305, de 02 de agosto de 2010, a qual é parte integrante da política nacional do meio ambiente. (BRASIL, Lei 12.305/2010)

As evidências que vivenciamos contemporaneamente trarão uma grave problemática ambiental contundentes. 
Os Resíduos sólidos de Serviços de Saúde (RSS) são a nomenclatura mais recente aos "resíduos hospitalares", denominação antiga e hoje inadequada, embora de uso consagrado. O gerenciamento dos resíduos hospitalares enquadrado na Política Nacional de Resíduos Sólidos (PNRS) com direcionamento dos resíduos de forma eficiente visando à proteção ambiental.

Os objetivos específicos evidenciam os cuidados, com os resíduos de serviços de saúde desde a coleta, até o descarte final (empresa coletora).

Portanto, essa estratégia, no conhecimento de como pode se realizar uma melhor segregação e com isso trazendo um acondicionamento correto destes resíduos, para evitar maiores riscos à saúde humana e a contaminação do meio ambiente.

Desta forma, o presente trabalho busca analisar as questões referentes à situação dos resíduos de serviços de saúde, expondo a gestão dos (RSS) e seu descarte final, com maior economia de custos, melhor qualidade e controle do manejo até seu descarte final, bem como apresentar uma revisão bibliográfica para analisar a destinação e segregação do descarte dos resíduos sólidos de serviços de saúde. Com a finalidade de levantar uma abordagem qualitativa referente à destinação dos resíduos de serviços de saúde, de acordo com as normas e diretrizes e leis regulamentadoras.

\section{RESÍDUOS DE SERVIÇOS DE SAÚDE}

Os Resíduos Sólidos de Serviços de Saúde (RSS) são a nova nomenclatura. Esses resíduos quando gerenciados inadequadamente, em quaisquer de seus processos de manejo, podem causar diversos danos à natureza, bem como ao meio ambiente, poluindo água, solo e ar, alterando fatores químicos, físicos e microbiológicos ambientais. (BARROS, 2012)

A diversidade dos geradores referente aos resíduos sólidos de serviços de saúde é um desafio a ser encarado pela sociedade em decorrência das diversas atividades e processos para melhores condições de saúde ambiental.

Os Resíduos de Serviços de Saúde (RSS) foram conhecidos por muito tempo como resíduos hospitalares. Porém, nessa antiga terminologia, encerrava apenas uma das atividades previstas em serviços de saúde. Ao se englobar todos os serviços de saúde na definição, tais resíduos englobam uma série de atividades relacionadas com prestação de serviços de assistência sanitária, tais como: hospitais, clinicas veterinárias, clínicas em geral, laboratórios de análises clínicas, ambulatórios, dentre diversas outras (BARROS, 2012, p.165). 
De acordo com capítulo II no artigo terceiro, inciso XVI, da lei federal $\mathrm{n}^{\circ}{ }^{12.305}$ de 02 de agosto de 2010, define-se resíduos sólidos, como:

[...] material, substância, objeto ou bem descartado resultante de atividades humanas em sociedade, a cuja destinação final se procede, se propõe proceder ou se está obrigado a proceder, nos estados sólido ou semissólido, bem como gases contidos em recipientes e líquidos cujas particularidades tornem inviável o seu lançamento na rede pública de esgotos ou em corpos d'água, ou exijam para isso soluções técnica ou economicamente inviáveis em face da melhor tecnologia disponível [...]. (BRASIL, LEI 12.305/2010).

Conforme a resolução do Conselho Nacional do Meio Ambiente (CONAMA) no 358 , de 29 de abril de 2005, no artigo primeiro e considerando a necessidade de ação integrada entre os órgãos federais, estaduais e municipais de meio ambiente, de saúde e de limpeza urbana com o objetivo de regulamentar o gerenciamento dos resíduos de serviços de saúde, resolve:

[...] Esta resolução aplica-se a todos os serviços relacionados com o atendimento à saúde humana ou animal, inclusive os serviços de assistência domiciliar e de trabalhos de campo; laboratórios analíticos de produtos para a saúde; necrotérios, funerárias e serviços onde se realizem atividades de embalsamamento, serviços de medicina legal, drogarias e farmácias inclusive as de manipulação; estabelecimentos de ensino e pesquisa na área da saúde, centro de controle de zoonoses; distribuidores de produtos farmacêuticos, importadores, distribuidores produtores de materiais e controles para diagnóstico in vitro, unidades móveis de atendimento à saúde; serviços de acupuntura, serviços de tatuagem, dentre outros similares $[\ldots]$.

(BRASIL, Resolução CONAMA nº 358/2005 p.I).

\subsection{Classificação dos resíduos de serviços de saúde}

Os resíduos de serviços de saúde possuem diferentes características, sendo biológicas, físicas e químicas, de modo que precisam de processos diferenciados em seu manejo, necessitando ou não de tratamento prévio a sua disposição final (SANTOS, SANTOS, 2019).

Conforme a RDC n. 222, de 28 de março de 2018, ANVISA e a RDC n.358, 29 de abril de 2005, CONAMA (Brasil, 2005), os resíduos hospitalares podem ser classificados em cinco grupos distintos, grupo A: Resíduos infectantes; grupo B: Resíduos de origem química; grupo C: Resíduos radioativos, grupo D: Resíduos comuns; grupo E: Resíduos perfurocortantes, conforme suas características e riscos que oferecem ao meio ambiente e a saúde (MARCHIORATO, 2017). 


\section{Quadroı: Símbolos de Identificação}

\begin{tabular}{|c|c|}
\hline $\begin{array}{l}\text { Os resíduos do srupo A sāo identificados pelo } \\
\text { símbolo de substância infectante, com rótulos de } \\
\text { fundo branco, desenho e contornos pretos. }\end{array}$ & \\
\hline $\begin{array}{l}\text { Os residuos do grupo B säo identificados através do } \\
\text { símbolo de risco associado e com discriminação de } \\
\text { substância química e frases de risco. }\end{array}$ & \\
\hline $\begin{array}{l}\text { Os rejeitos do grupo C säo representados pelo } \\
\text { símbolo internacional de presença de radiaçäo } \\
\text { ionizante (trílólo de cor magenta) em rótulos de } \\
\text { fundo amarelo e contornos pretos, acrescido da } \\
\text { expressäo MATERIAL RADIOATIVO. }\end{array}$ & \\
\hline 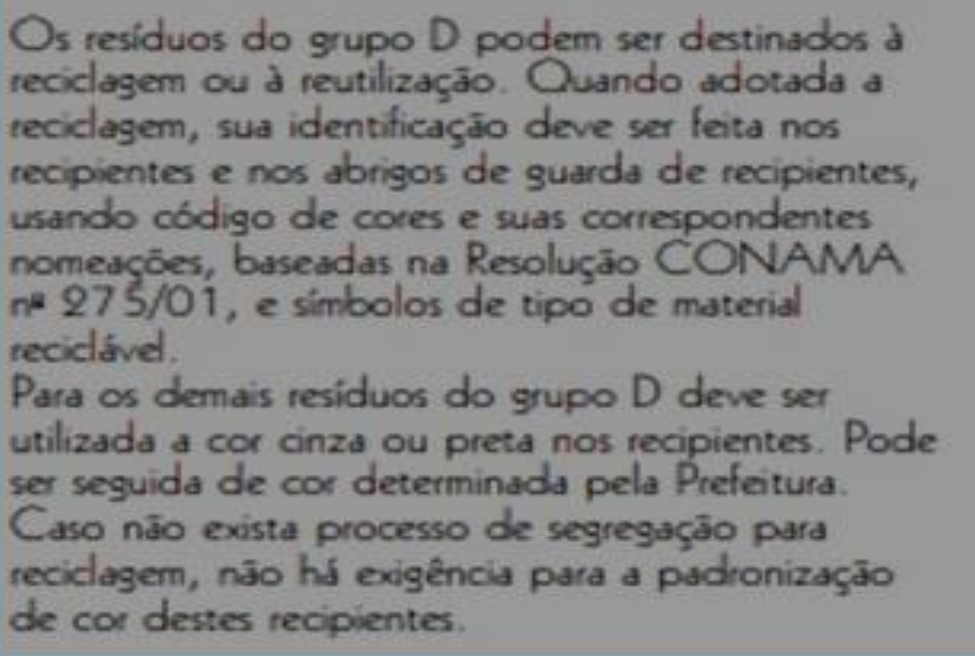 & $\begin{array}{l}\text { VDEO } \\
\text { PLNTICO } \\
\text { PAPE } \\
\text { METAL } \\
\text { ORGANICO }\end{array}$ \\
\hline $\begin{array}{l}\text { Os produtos do grupo E sào identificados pelo } \\
\text { simbolo de substânca infectante, com rótulos de } \\
\text { fundo branco, desenho e contornos pretos, } \\
\text { acrescido da inscrí̧ão de RESiDUO } \\
\text { PERFUROCORTANTE, indicando o risco que } \\
\text { apresenta o resíduo. }\end{array}$ & (O) \\
\hline
\end{tabular}

Fonte: Brasil. Ministério da Saúde. Agência Nacional de Vigilância Sanitária. Manual de gerenciamento de resíduos de serviços de saúde.p.42. 


\section{Grupo A - Resíduos infectantes}

Os resíduos dessa categoria são os que mais oferecem perigo, pois apresentam risco à saúde pública e ao meio ambiente em virtude de apresentarem agentes biológicos que podem causar infecções. Como exemplos desses resíduos estão: seringas, já utilizadas, placas e lâminas de laboratórios, restos de órgãos, vacinas de microorganismos vivos, sangue e hemoderivados, excreções, secreções e líquidos orgânicos meios de cultura, tecido humano, resíduos advindos de área de isolamento, entre outros. $\mathrm{O}$ acondicionamento de tais resíduos deve ser feito em sacos plásticos branco leitoso e impermeável, seu destino final é a incineração (CARDOSO, 2016).

Tabela: Subgrupos do Grupo A

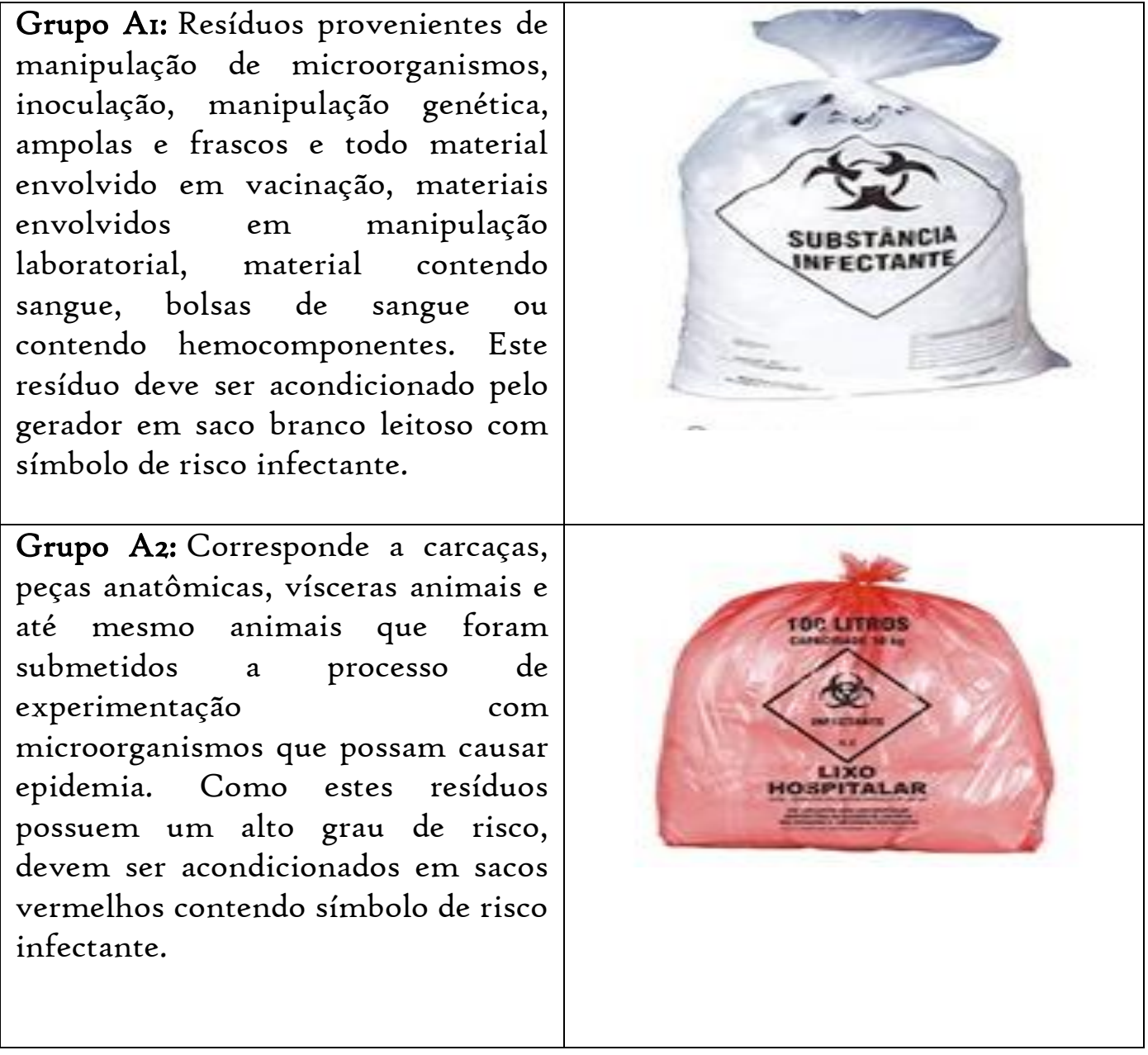




Grupo A3: Peças anatômicas
(membros humanos), produtos de
fecundação sem sinais vitais, com
peso inferior a 5oo gramas e estatura
menor que 25 cm, devem ser
acondicionados pelo gerador em saco
vermelho com símbolo de risco
infectante.
Grupo A4: Kits de linha arteriais,
filtros de ar e de gases aspirados de
áreas contaminadas, sobras de
laboratório contendo fezes, urina e
secreções, tecidos e materiais
utilizados em serviços de assistência
á saúde humana ou animal, órgãos e
tecidos humanos, carcaças, peças
anatômicas de animais, cadáveres de
animais e outros resíduos que não
tenham contaminação ou mesmo
suspeita de contaminação com
doença ou microorganismos de
importância epidemiológica. Estes
resíduos devem ser acondicionados
pelo gerador em sacos branco leitoso
com símbolo de risco infectante.
Grupo As: Órgãos, tecidos, fluidos e
todos os materiais envolvidos na
atenção à saúde de indivíduos ou
animais com suspeita ou certeza de
contaminação por príns (agentes
infecciosos compostos por proteínas
modificadas). Estes materiais devem
ser acondicionados pelo gerador em 2
sacos vermelhos (um dentro de
outro) contendo símbolo de risco
infectante.




\section{Grupo B- Resíduos de origem química}

O risco envolvendo tais resíduos se deve às suas características químicas. Resíduos pertencentes a esse grupo podem ser inflamáveis, corrosivos, tóxicos, reativos, ente outros. Como exemplo, citamos: medicamentos, reagentes, drogas quimioterápicas e produtos por ela contaminados, resíduos farmacêuticos, resíduos químicos perigosos, entre outros. O acondicionamento de tais resíduos deve ser feito ou de modo a conservar o produto em sua embalagem original, ou transferi-lo para um recipiente inquebrável. Após isso, é preciso devolver o produto ao seu fabricante, que se encarregará de descartá-lo, obedecendo às normatizações específicas (CARDOSO, 2016).

\section{Grupo C - Resíduos radioativos}

Nesse grupo enquadram-se os materiais radioativos ou contaminados com radionuclídeos provenientes dos laboratórios de análises clinicas, dos serviços de medicina nuclear e da radioterapia. Esse tipo de resíduos contém radionuclídeos em quantidades especificadas nas normas da comissão nacional de energia nuclear. Citamos como exemplos os raios $\mathrm{X}$ e os rejeitos de exame de medicina nuclear, entre outros. $\mathrm{A}$ acomodação desse tipo de resíduo deve ser realizada em recipientes blindados, de modo a evitar vazamentos radioativos, e ser destinada á Cnem para devido descarte (CARDOSO, 2016).

\section{Grupo D- Resíduos comuns}

Essa categoria compreende todos os resíduos que não se enquadram nos grupos descritos anteriormente, isto é, são resíduos da atividade administrativa, dos serviços de variação e de limpeza de jardins e de restos de alimentos que não entraram em contato com os pacientes. Esse grupo consiste no lixo menos tóxico que provém das instituições hospitalares, pois não é contaminado, mesmo assim, tais resíduos têm certo grau de perigo, de modo que não podem ser descartados no meio ambiente. Como exemplos, citamos as sobras de alimentos, os papeis e os resíduos de gesso, entre outros. $\mathrm{O}$ acondicionamento deve ser feito de acordo com o material lata, vidro, papel etc, assim como é feitos nos domicílios. O destino final, para grande parte desses resíduos, é a reciclagem e a reutilização. Tais resíduos provem não só do atendimento a pacientes, mas também em 
todos os ambientes existentes nas instituições ou nas unidades de saúde que executam atividades de atendimento medico, tanto para seres humanos quanto para animais. Alem disso, esses resíduos também são oriundos de pesquisas em laboratórios de farmacologia. Para finalizar existe mais uma categoria de resíduos hospitalares, a qual e específica das instituições hospitalares (CARDOSO, 2016).

\section{Grupo e- Resíduos perfurocortantes}

Consideramos nesse grupo os objetos perfurocortantes capazes de causar punctura ou corte, como lâminas de barbear, bisturi agulhas, escalpes e ampolas de vidro. A recomendação e de que tais materiais sejam devidamente embalados e acomodados em caixas. O destino final é a incineração.

Assim como a norma da ABNT 12808:2016, para seus efeitos deste documento os resíduos de saúde são classificados de acordo com sua natureza de risco conforme, biológico, o qual se subdivide em: microbiológico; sangue, hemoderivados e líquidos corpóreos; assistência ao paciente; cirúrgico, obstétrico e anatomopatológico, e, resíduos de animais; e outro grupo químico; outro grupo de rejeito radioativo; outro grupo de perfurante e cortante; comum ou sem risco à saúde pública (Marchiorato, 2017).

\section{GERENCIAMENTO DOS RESÍDUOS DE SAÚdE}

O gerenciamento dos RSS deve levar em consideração a separação dos resíduos na fonte geradora, considerado perigoso, infectante e/ou perfurocortante eventualmente estando misturados com outros tipos de resíduos, isso acarretaria dentre outras consequências, o aumento do custo de gerenciamento dos RSS (BARROS, 2012, p.169).

De acordo com a Agência Nacional de Vigilância Sanitária (ANVISA), a RDC, no 222 de 28 de março de 20I8, na seção III do artigo terceiro no inciso XLI, para efeito desta resolução são adotadas as seguintes definições:

\footnotetext{
Plano de gerenciamento dos resíduos de serviços de saúde (PGRSS): documento que aponta e descreve todas as ações relativas ao gerenciamento dos resíduos de serviços de saúde, observadas suas características e riscos, contemplando os aspectos referentes à geração, identificação, segregação, acondicionamento, coleta, armazenamento, transporte, destinação e disposição final ambientalmente adequada, bem como as ações de proteção à saúde pública, do trabalhador e do meio ambiente (ANVISA, RDC, 2018).
} 
As técnicas utilizadas corretamente para o manejo dos resíduos dos estabelecimentos de serviços de saúde são necessárias para permitir a segurança dos pacientes, visitantes e funcionários, tendo em vista que o gerenciamento dos resíduos serviços saúde pode proteger a comunidade e o meio ambiente (SCHALCH, I99o apud por SANTOS, 2019, p.15).

Conforme a resolução RDC №. 222, de 28 de março de 2018, capítulo I, seção II, com abrangência:

Art.2을 Esta resolução se aplica aos geradores de resíduos de serviços de saúde RSS cujas atividades envolvam qualquer etapa do gerenciamento dos RSS, sejam eles públicos e privados, filantrópicos, civis ou militares, incluindo aqueles que exercem ações de ensino e pesquisa. (BRASIL, RDC n.222, 2018)

Os Resíduos de Serviços de saúde ocasionaram entre os órgãos regulamentadores de leis normativas, alguns desafios com relação ao gerenciamento adequado e seguro desses resíduos, seja em nível municipal, ou/e nacional, (SANTOS, SANTOS, 2019, p.22).

De acordo com a resolução RDC №. 222, de 28 de marco de 20I8, capítulo II, no “Art. $4^{\circ} \mathrm{O}$ gerenciamento dos RSS deve abranger todas as etapas de planejamento dos recursos físicos, dos recursos materiais e da capacitação dos recursos humanos envolvidos”.

A gestão abrange as operações referentes às tomadas de decisões nos aspectos administrativo, operacional, financeiro, social e ambiental e tem na preparação do seu plano integrado um importante mecanismo na parte do gerenciamento de resíduos em todas as suas etapas como a geração, classificação, segregação, acondicionamento, armazenamento, transporte, destinação até a disposição final de maneira ambiental apropriada, possibilitando que se estabeleçam de forma sistemática e integrada em cada uma delas, metas, programas, sistemas organizacionais e tecnologias, compatíveis com a realidade local (ANVISA, 2018).

Assim sendo, o planejamento, a adequação dos procedimentos de manejo, o sistema de sinalização e o uso de equipamentos apropriados, não é apenas possível diminuir os riscos, como reduzir as quantidades de resíduos a serem tratados e, ainda, promover o reaproveitamento de grande parte ou/e, pela segregação de boa parte dos materiais recicláveis, reduzindo os custos de seu tratamento e disposição final que normalmente são altos (ANVISA, 2018).

Através da $15^{\text {a }}$ edição ininterrupta do Panorama dos Resíduos Sólidos no Brasil, visualizamos atualização anual dos RSS. Os resultados (apresentados na Figura i e 2) 
provêm de uma pesquisa feita pela Abrelpe junto aos municípios e às empresas do setor. A partir dos dados, fez-se uma projeção para todo o Brasil. O levantamento aponta que, em 2018, 4.540 municípios prestaram serviços de coleta, tratamento e disposição final de 252.948 toneladas de RSS, o equivalente a 1,2 quilos por habitante ao ano. Isso representa uma diminuição de $1,55 \%$ em relação a 2017 (1,94\% em termos per capita). (ABRELPE, 2018/2019).

Figura 1: Quantidade de RSS coletada pelos municípios.

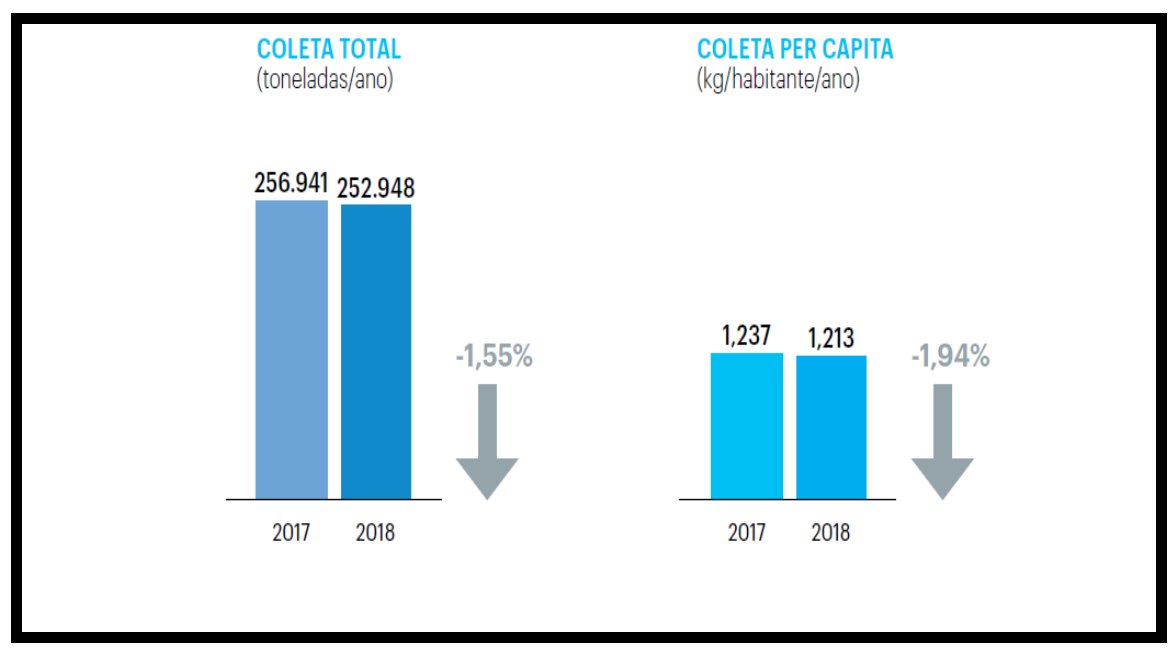

Fonte: Abrelpe/IBGE.

Figura 2: Tipo de Destinação final dos RSS coletados pelos municípios.

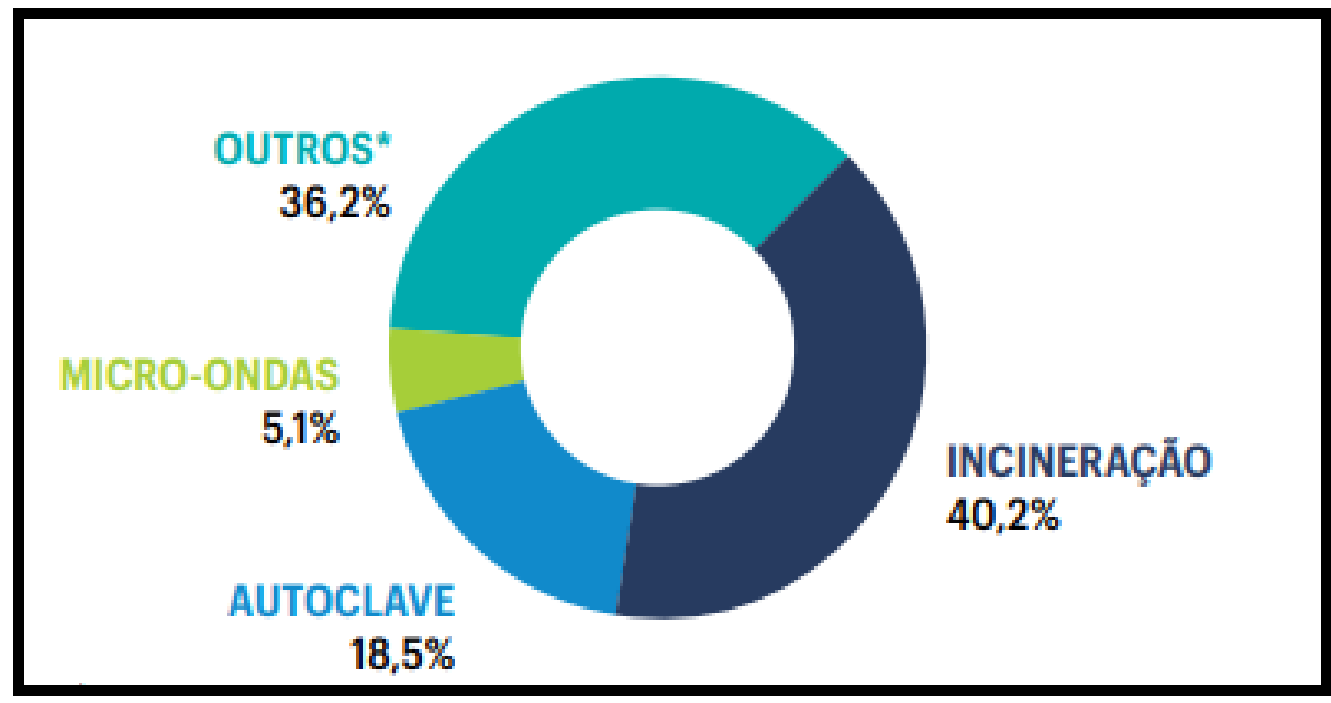

Fonte: Abrelpe. 


\section{I Segregação/Separação}

De acordo com a RDC da ANVISA no. 222/2018, a etapa de segregação consiste na separação dos resíduos no momento e local de sua geração, de acordo com as características físicas, químicas, biológicas, o seu estado físico e os riscos envolvidos.

A segregação é uma etapa de grande relevância para que o gerenciamento seja eficaz. Ter embalagens e locais específicos, sendo eles identificados em todos os locais geradores para cada tipo de resíduo, proporciona êxito à segregação.

Um bom gerenciamento dos resíduos de serviços de saúde deve ter como princípio a segregação na fonte, o que resulta na redução do volume de resíduos com potencial de risco e na incidência de acidentes ocupacionais.

Para efetivar a gestão com base no princípio de minimização dos riscos adicionais dos RSS, o gestor deve adotar procedimentos de segregação de acordo com o tipo de resíduo, no próprio local de geração. As vantagens de praticar a segregação na origem são: redução dos riscos para a saúde e o ambiente, impedindo que os resíduos potencialmente infectantes ou especiais, que geralmente são frações pequenas, contaminem os outros resíduos gerados no hospital; - diminuição de gastos, já que apenas terá tratamento especial uma fração e não todos resíduos (ANVISA, 2018).

\subsection{Identificação}

De acordo com a RDC da ANVISA no. 222/2018, a identificação é o conjunto de medidas que permite o reconhecimento dos riscos presentes nos resíduos acondicionados, de forma clara e legível em tamanho proporcional aos sacos, coletores e seus ambientes de armazenamento.

A identificação deve constar nos sacos de acondicionamento, nos recipientes de coleta interna e externa, nos recipientes de transporte interno e externo e nos locais de armazenamento, em local de fácil visualização, em que se utilizem símbolos, cores e frases, atendendo aos parâmetros referenciados na norma NBR 7500 da ABNT, além de outras exigências relacionadas à identificação de conteúdo e ao risco específico de cada grupo de resíduos. 


\subsection{Acondicionamento}

De acordo com a RDC da ANVISA n․ 222/2018, esta etapa consiste no ato de embalar os resíduos segregados em sacos ou recipientes que evitem vazamentos, e quando couber, sejam resistentes às ações de punctura, ruptura e tombamento, e que sejam adequados física e quimicamente ao conteúdo acondicionado.

$\mathrm{Um}$ acondicionamento inadequado compromete a segurança do processo e o encarece. Recipientes inadequados ou improvisados (pouco resistentes, mal fechados ou muito pesados), construídos com materiais sem a devida proteção, aumentam o risco de acidentes de trabalho. Os resíduos não devem ultrapassar $2 / 3$ do volume dos recipientes.

$\mathrm{O}$ acondicionamento dos resíduos na origem consiste em controlar os riscos para a saúde e facilitar as operações de coleta, armazenamento externo e transporte, sem prejudicar o desenvolvimento natural das atividades do estabelecimento. Os recipientes utilizados necessitam ser apropriados para cada tipo de resíduo, sendo que o tamanho, o peso, a cor, a forma e o material devem garantir uma apropriada identificação, facilitar as operações de transporte e limpeza, ser herméticos para evitar exposições desnecessárias e estar integrados às condições físicas e arquitetônicas do local. Esses recipientes são complementados com o uso de sacos plásticos para efetuar uma embalagem apropriada dos resíduos (ORGANIZAÇÃO PAN-AMERICANA DE SAÚDE, I997).

\subsection{Coleta e tratamento interno}

De acordo com a RDC da ANVISA no. 222/2018, a coleta e transporte interno dos RSS consistem no traslado dos resíduos dos pontos de geração até local destinado ao armazenamento temporário ou armazenamento externo.

O transporte interno deve estabelecer rotas de coletas que sejam em horários diferentes das refeições dos pacientes, das medicações e outras rotinas que o serviço entender que possa colocar em risco a segurança dos pacientes ou dos profissionais de saúde ou dos próprios profissionais envolvidos com a limpeza e higienização.

A coleta deve ser feita separadamente, de acordo com o grupo de resíduos e em recipientes específicos a cada grupo de resíduos. 
Art.26 O coletor utilizado para transporte interno deve ser constituído de material liso, rígido, lavável, impermeável, provido de tampa articulada ao próprio corpo do equipamento, cantos e bordas arredondados.

Os coletores com mais de quatrocentos litros de capacidade devem possuir válvula de dreno no fundo.

\subsection{Armazenamento temporário}

De acordo com a RDC da ANVISA nº. 222/2018, armazenamento temporário é uma guarda temporária dos coletores de resíduos de serviços de saúde, em ambiente próximo aos pontos de geração, visando agilizar a coleta no interior das instalações e otimizar o deslocamento entre os pontos geradores e o ponto destinado à apresentação para coleta externa.

Dependendo da distância entre os pontos de geração de resíduos e do armazenamento externo, poderá ser dispensado o armazenamento temporário, fazendo-se o encaminhamento direto ao local de armazenamento para coleta externa. Não poderá ser feito armazenamento temporário com disposição direta dos sacos sobre o piso, sendo obrigatória a conservação dos sacos em recipientes de acondicionamento. Podendo ser feito em carrinhos ou contenedores, um para cada grupo de resíduos, em quantidade suficiente para atender à demanda diária.

A sala para guarda de recipientes de transporte interno de resíduos deve ter pisos e paredes lisas e laváveis, sendo o piso, além disso, resistente ao tráfego dos recipientes coletores. Deve possuir iluminação artificial e área suficiente para armazenar, no mínimo, dois recipientes coletores, para o posterior traslado até a área de armazenamento externo. Para melhor higienização é recomendável a existência de ponto de água e ralo sinfonado com tampa escamoteável (ANVISA, 2018).

\subsection{Armazenamento externo}

De acordo com a RDC da ANVISA no. 222/2018, o armazenamento externo consiste no acondicionamento dos resíduos em abrigo, em recipientes coletores adequados, em ambiente exclusivo e com acesso facilitado para a coleta externa. 
O abrigo de resíduos deve ser dimensionado de acordo com o volume de resíduos gerados, com capacidade de armazenamento compatível com a periodicidade de coleta do sistema de limpeza urbana local.

O local desse armazenamento externo de RSS deve apresentar acessibilidade (o ambiente deve estar localizado e construído de forma a permitir acesso facilitado para os recipientes de transporte e para os veículos coletores); exclusividade (o ambiente deve ser utilizado somente para o armazenamento de resíduos); segurança (o ambiente deve reunir condições físicas estruturais adequadas, impedindo a ação do sol, chuva, ventos etc. e que pessoas não autorizadas ou animais tenham acesso ao local); higiene e saneamento (deve haver local para higienização dos carrinhos e coletores de resíduos). O ambiente deve contar com boa iluminação e ventilação e ter pisos e paredes revestidos com materiais resistentes aos processos de higienização, como azulejos, porcelanatos ou tinta epóxi, por exemplo (ANVISA, 2018).

\subsection{Coleta e transporte externo}

De acordo com a RDC da ANVISA no. 222/2018, a coleta e transporte externos são a remoção dos resíduos de serviços de saúde do abrigo externo até a unidade de tratamento ou outra destinação, ou disposição final ambientalmente adequada, utilizando-se de técnicas que garantam a preservação das condições de acondicionamento e a integridade dos trabalhadores, da população e do meio ambiente.

No transporte dos RSS podem ser utilizados diferentes tipos de veículos, de pequeno até grande porte, dependendo das definições técnicas dos sistemas municipais. Geralmente para esses resíduos são utilizados dois tipos de carrocerias: montadas sobre chassi de veículos e do tipo furgão, ambas sem compactação, para evitar que os sacos se rompam. Os sacos nunca devem ser retirados do suporte durante o transporte, também para evitar ruptura. Para que o gerenciamento dentro e fora do estabelecimento possa ser eficaz é necessário que o poder público se envolva e estabeleça leis e regulamentos sobre a gestão de resíduos de serviços de saúde, assumindo o seu papel de gestor local. O pessoal envolvido na coleta e no transporte dos RSS deve observar rigorosamente a utilização dos EPIs e EPCs adequados. 
Ao final de cada turno de trabalho, o veículo coletor deve ser submetido à limpeza e desinfecção simultânea, mediante o uso de jato de água, preferencialmente quente e sob pressão. Esses veículos não podem ser lavados em postos de abastecimento comuns. $\mathrm{O}$ método de desinfecção do veículo deve ser alvo de avaliação por parte do órgão que licencia o veículo coletor (ANVISA, 2018).

\subsection{Tratamento}

Segundo o CONAMA 358 (2005): Sistema de tratamento de resíduos de serviços de saúde: conjunto de unidades, processos e procedimentos que alteram as características físicas, físico-químicas, químicas ou biológicas dos resíduos, podendo promover a sua descaracterização, visando à minimização do risco à saúde pública, a preservação da qualidade do meio ambiente, a segurança e a saúde do trabalhador.

\subsection{Destinação final}

Segundo a resolução do CONAMA, nº. 358/2005, a disposição final de resíduos de serviços de saúde consiste na prática de dispor os resíduos sólidos no solo previamente preparado para recebê-los, de acordo com critérios técnico-construtivos e operacionais adequados, em consonância com as exigências dos órgãos ambientais competentes. Conforme o Manual de Saneamento, elaborado pela Fundação Nacional de Saúde (FUNASA, 2006), a disposição final adequada dos resíduos hospitalares deve ser realizada em aterro controlado ou sanitário, 28 RAHIS - Revista de Administração Hospitalar e Inovação em Saúde - jan./jun. 2oIr que será implantada (dependendo do caso), pelo projeto técnico que siga rigorosamente a Norma da Associação Brasileira de Normas Técnicas, o qual determina os métodos e processos de apresentação de projetos tanto de aterros controlados como de aterros sanitários de resíduos sólidos urbanos.

Conforme a Resolução da Diretoria Colegiada - RDC no 222, de 28 de março de 2018, na seção V Destinação diz:

Art. 40 Os RSS que não apresentam risco biológico, químico ou radiológico podem ser encaminhados para reciclagem, recuperação, reutilização, compostagem, aproveitamento energético ou logística reversa.

Art. 4I Os rejeitos que não apresentam risco biológico, químico ou radiológico devem ser encaminhados para disposição final ambientalmente adequada. 
Art. 42 As embalagens primárias vazias de medicamentos cujas classes farmacêuticas constem no Art. 59 desta Resolução devem ser descartadas como rejeitos e não precisam de tratamento prévio à sua destinação.

Art. 45 A destinação dos medicamentos recolhidos ou apreendidos, objetos de ações de fiscalização sanitária, deve seguir a determinação prevista no art. 59 desta Resolução. (BRASIL, RDC n.222, 2018).

Por oportuno, demonstra-se relação das regiões do Brasil (Figura 3 à Figura 7):

Fig. 3: Tipo de destinação final dos RSS coletados pelos municípios na região norte.

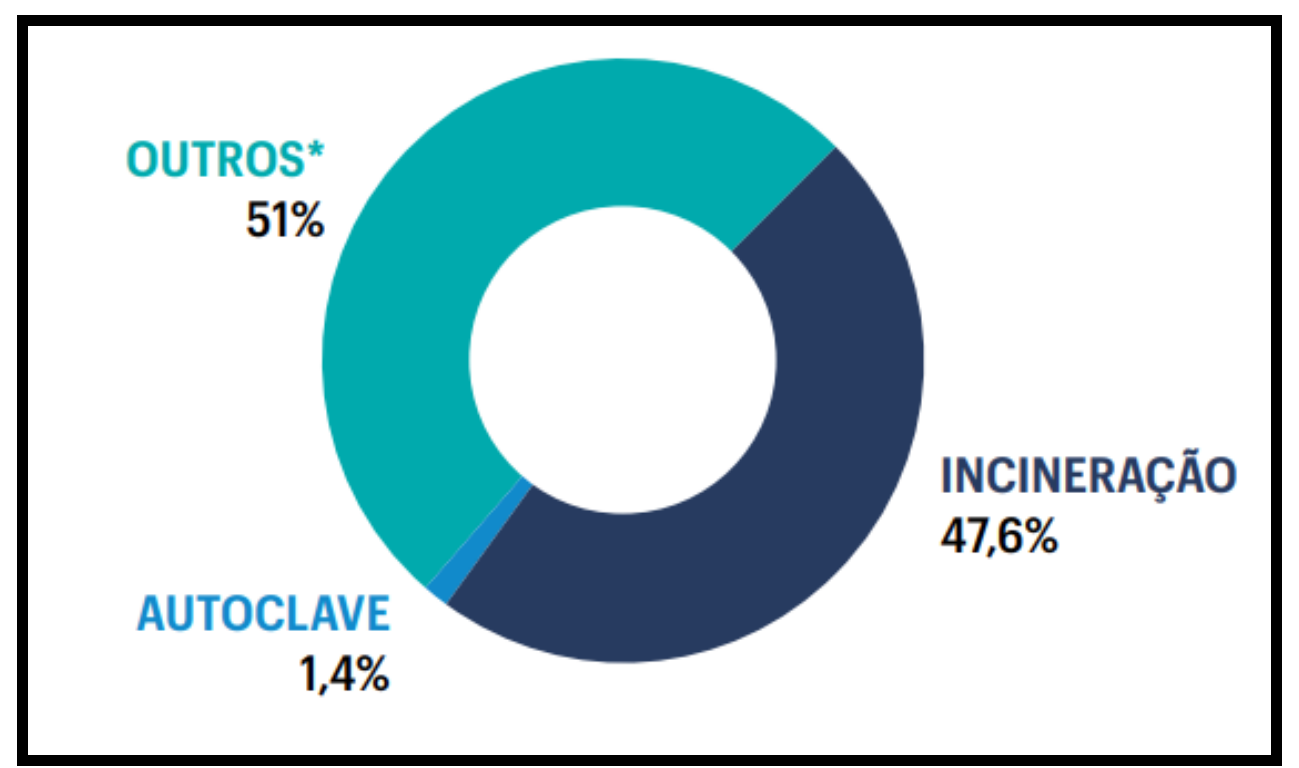

Fonte: Abrelpe. $15^{\underline{a}}$ ed. p.43

Fig. 4: Tipo de destinação final dos RSS coletados pelos municípios na região nordeste.

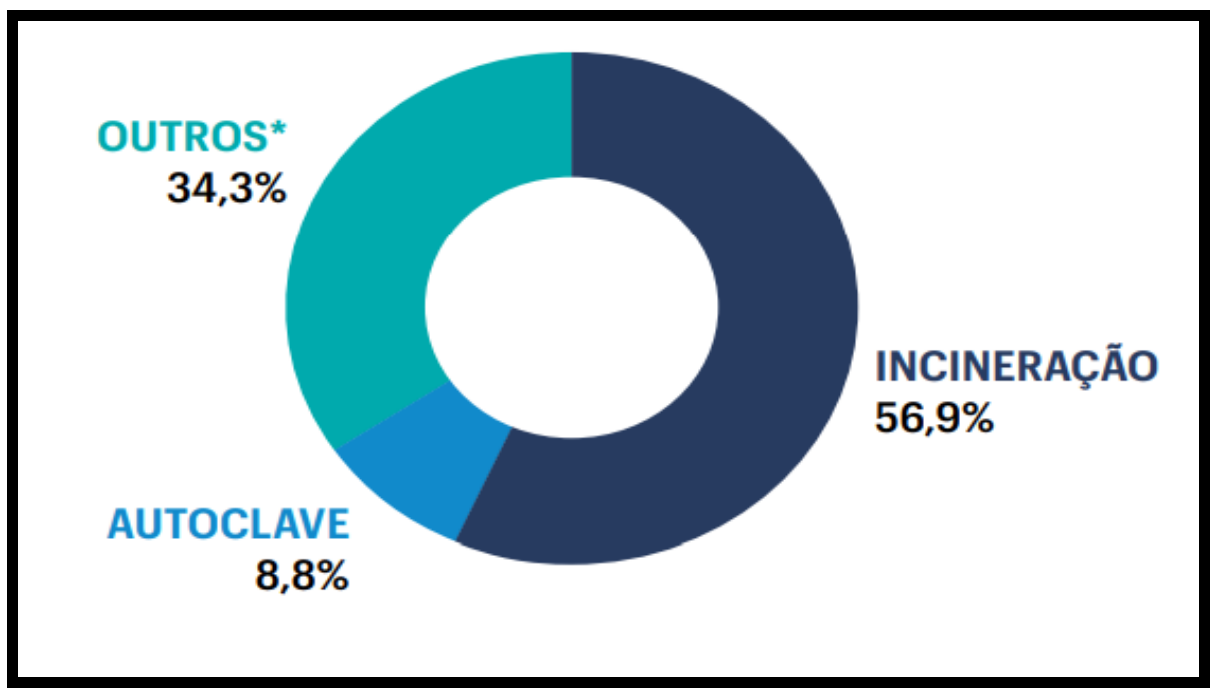

Fonte: Abrelpe. $15^{\underline{a}}$ ed. p.45. 
Fig. 5: Tipo de destinação final dos RSS coletados pelos municípios na região centro-oeste.

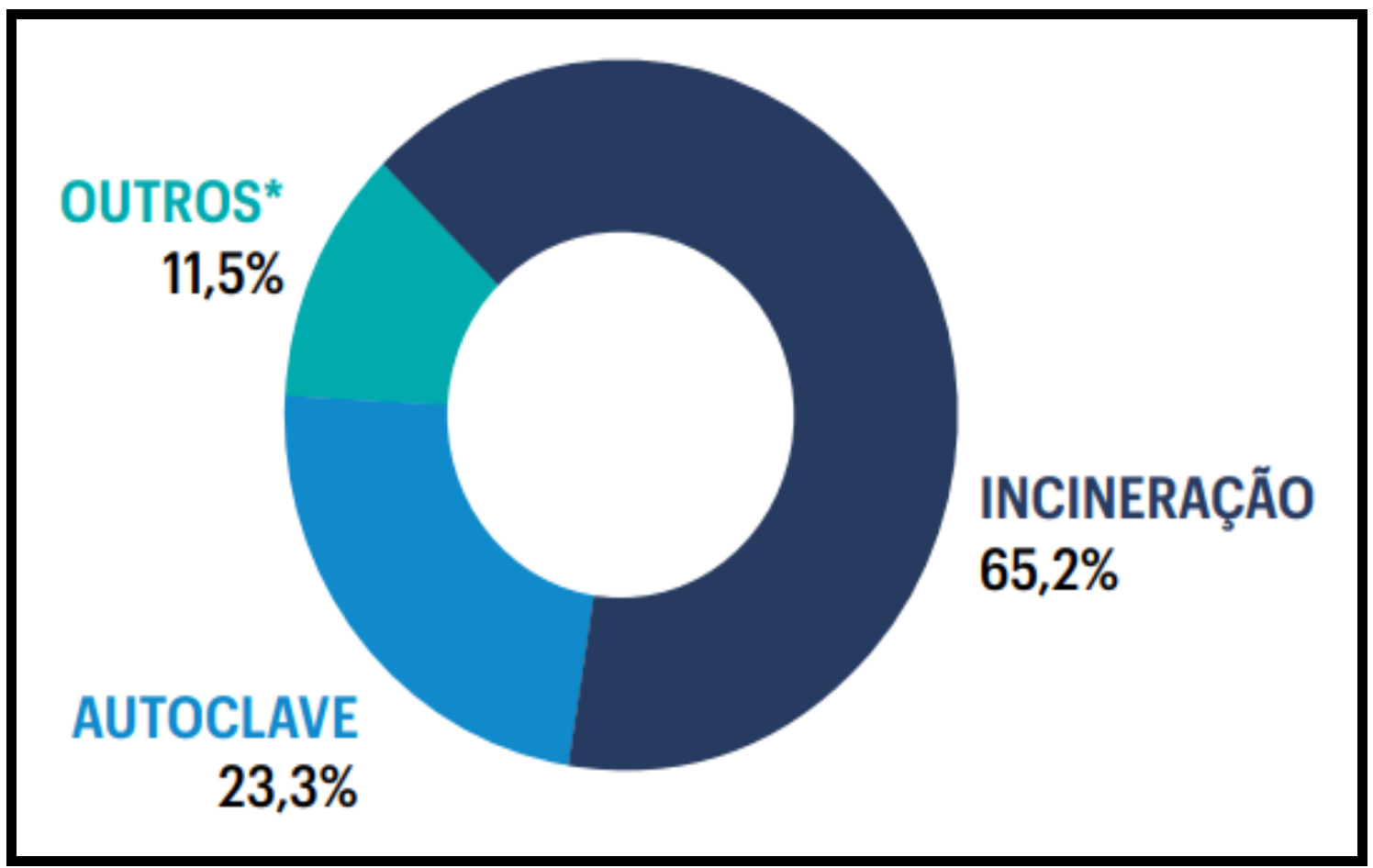

Fonte: Abrelpe. $15^{\underline{a}}$ ed. p.46.

Fig. 6: Tipo de destinação final dos RSS coletados pelos municípios na região sudeste.

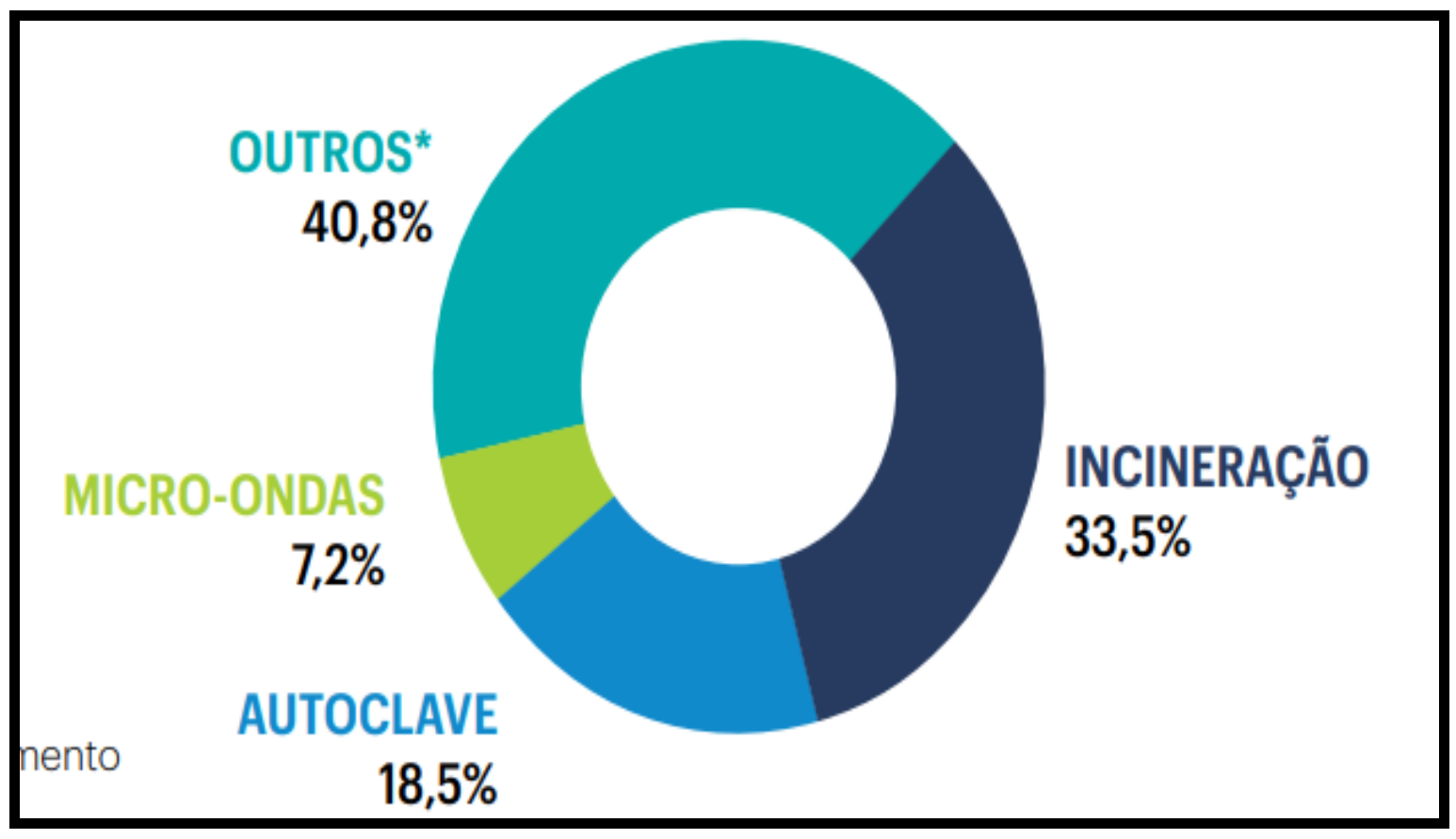

Fonte: Abrelpe. $15^{\underline{a}}$ ed. p.47. 
Fig. 7: Tipo de destinação final dos RSS coletados pelos municípios na região sul.

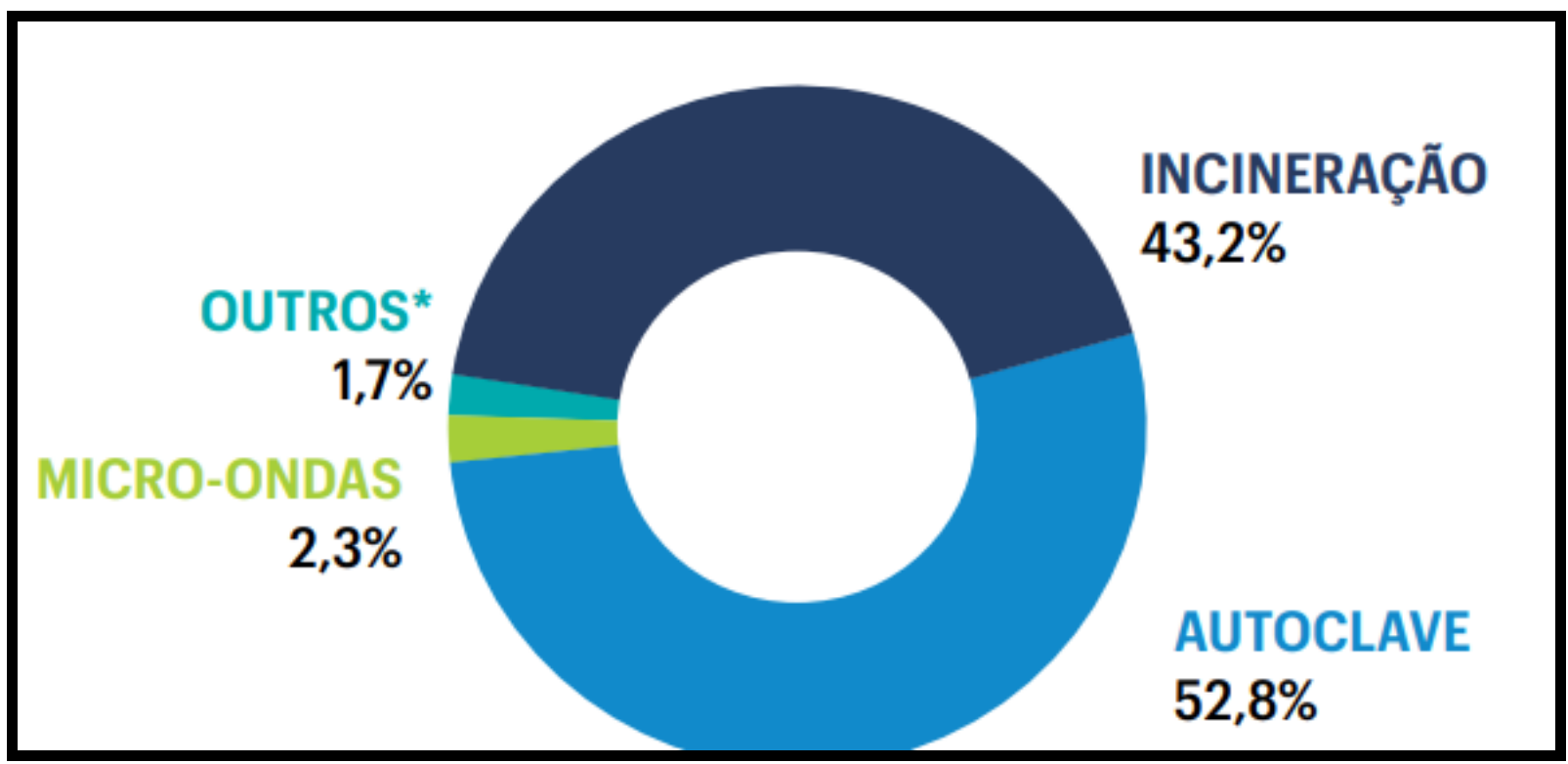

Fonte: Abrelpe. $15^{\underline{a}}$ ed. p.48.

\section{LEGISLAÇÃO}

No Brasil, há previsão na Constituição da República Federativa do Brasil de 1988 da defesa do meio ambiente, inclusive mediante tratamento diferenciado, conforme o impacto ambiental dos produtos e serviços e de seus processos de elaboração e prestação.

Conforme o artigo 225 da Constituição Federal diz: Todos têm direito ao meio ambiente ecologicamente equilibrado, bem de uso comum do povo e essencial à sadia qualidade de vida, impondo-se ao poder público e à coletividade o dever de defendê-lo e preservá-lo para as presentes e futuras gerações.

Há política pública para os resíduos de serviço de saúde, publicada em 02 de agosto de 2010, Lei 12.305, a qual foi criada a Política Nacional de Resíduos Sólidos, dispondo sobre princípios, objetivos e instrumentos, bem como sobre as diretrizes relativas à gestão integrada e ao gerenciamento de resíduos sólidos, responsabilidades dos geradores e do Poder Público.

Esta lei foi regulamentada pelo Decreto n. 7.404, de 23 de dezembro de 2010, que institui a Política Nacional de Resíduos Sólidos, cria o Comitê Interministerial da Política Nacional de Resíduos Sólidos e o Comitê Orientador para a Implantação dos Sistemas de Logística Reversa, e dá outras providências. 
Conforme o artigo no 13 da Lei Federal no 12.305/2010, que trata da Política Nacional de Resíduos Sólidos (PNRS), define Resíduos de serviços de saúde RSS como aqueles que são gerados nas instituições que prestam serviços de saúde, conforme definido em regulamento ou em normas estabelecidas pelos órgãos do Sistema Nacional de Meio Ambiente (Sisnama) e do Sistema Nacional de Vigilância Sanitária (SNVS).

Por derradeiro, vale destacar a promulgação do Decreto n. I0.388, de 05 de junho de 2020, o qual regulamenta o § I- do caput do art. 33 da Lei no 12.305 , de 2 de agosto de 2010, e institui o sistema de logística reversa de medicamentos domiciliares vencidos ou em desuso, de uso humano, industrializados e manipulados, e de suas embalagens após o descarte pelos consumidores, com a participação de fabricantes, importadores, distribuidores, comerciantes e consumidores, nos termos do disposto no Decreto no $7 \cdot 404$, de 23 de dezembro de 2010 .

\section{CONSIDERAÇÕES FINAIS}

É conclusiva para este trabalho a importância de um Plano de Gerenciamento de Resíduos Sólidos de Serviços de Saúde (PGRSS) para qualquer instituição publica ou privada. Porém são vários os desafios que esses estabelecimentos estão enfrentando quanto à utilização da legislação em vigor como base para seu processo de trabalho, comprometendo assim a implantação do Plano de Gerenciamento Resíduos de Serviços de Saúde (PGRSS).

Essas circunstâncias estão relacionadas com a falta de treinamentos de capacitação no âmbito geral sobre a gestão do gerenciamento dos resíduos de serviços de saúde (RSS), ausência dada ao tema e ao descumprimento prescrito na legislação.

Perante as precariedades encontradas na gestão dos resíduos de serviços de saúde preconiza-se não apenas investimento público na parte da gestão dos resíduos sólidos, mas, também, uma conformidade perante aos profissionais dos Serviços de Saúde com a vigilância sanitária municipal, com a aplicação dos conceitos da educação sanitária referente a melhoria na infraestrutura, bem como maior rigor no controle do gerenciamento dos resíduos, da coleta externa até o destino final, minimizando os riscos à saúde pública e ao meio ambiente. 
De acordo com estudos e pesquisas realizadas sobre o gerenciamento dos resíduos sólidos de serviços de saúde, sabe-se que através do sistema das políticas públicas, pode trazer uma maior efetivação para incentivar as instituição sobre o quanto é de importância se ter um incentivo fiscal para o efetivo das adesões através da lei 12.305/2010 tanto para legislação federal quanto estadual e municipal.

\section{REFERÊNCIAS BIBLIOGRAFICAS}

ABRELPE. Associação brasileira de empresas de limpezas públicas e resíduos especiais. Disponível em:<〈http://abrelpe.org.br/download-panorama-2018-2019/ >>. Acesso dia 20 de junho 2020.

ASSOCIAÇÃO BRASILEIRA DE EMPRESAS DE LIMPEZAS PÚBLICAS E RESÍDUOS ESPECIAIS - ABRELPE. Panorama dos Resíduos Sólidos no Brasil 2013. São Paulo: Abrelpe, 2016.

ATITUDE AMBIENTAL. Disponível em: http://atitudeambiental.com/classe.html. Acesso dia I5 de junho d e2020 ás 22:06.

BARROS, R. M. Tratado sobre residuos: gestão, uso e sustentabilidade. Rio de Janeiro: Interciência, 2012.

BARROS, Raphael Tobias de Vasconcelos. Elementos de resíduos sólidos. Belo Horizonte: Tessitura, 2012.

BRASIL. Associação Brasileira de Normas Técnicas. NBR 6II8: Projeto de estruturas de concreto - procedimento. Rio de Janeiro: ABNT, 2014.

BRASIL. Associação brasileira de normas técnicas. Resíduos de serviços de saúde - NBR I2.808. RIO DE JANEIRO, 2016. 
BRASIL. Agência Brasileira de Vigilância Sanitária. Resolução RDC №. 222, de 28 de março de 2018. Regulamenta as Boas Práticas de Gerenciamento dos Resíduos de Serviços de Saúde e dá outras providências.

Disponívelem:http://portal.anvisa.gov.br/documents/33852/271855/RDC+222+de+Mar\%C 3\%A7o+de+2018+COMENTADA/edd85795-17a2-4ere-99ac-df6badieooce. Acesso em: 20/08/2019.

BRASIL. Constituição da República Federativa do Brasil de 1988. Disponível em: http://www.planalto.gov.br/ccivil_03/constituicao/constituicao.htm.Acesso em: 20/08/2019.

BRASIL. Lei n. 12.305, de 02 de agosto de 2010. Disponível em: http://www.planalto.gov.br/ccivil_03/_ato2007-2010/2010/lei/li2305.htm. Acesso em: 20/08/2019.

BRASIL. Decreto n. 7.404, de 23 de dezembro de 2010. Regulamenta a Lei no 12.305, de 2 de agosto de 2010. Disponível em: http://www.planalto.gov.br/ccivil_03/_ato20072010/2010/Decreto/D7404.htm. Acesso em: 20/o8/2019.

BRASIL.https://www.senado.leg.br/atividade/const/coni988/coni988_26.06.2019/art_225_ .asp. Acesso 13-05-2020.

BRASIL. CONSELHO NACIONAL DE MEIO AMBIENTE. Resolução CONAMA no 358 de 29 abril de 2005. Dispõe sobre o tratamento e a disposição final dos resíduos dos serviços de saúde e dá outras providencias. Disponível em: http://www2.mma.gov.br/port/conama/legiabre.cfm?codlegi=462. Acesso em: 20/09/2019.

BRASIL. Ministério da Saúde. Agência Nacional de Vigilância Sanitária. Manual de gerenciamento de resíduos de serviços de saúde / Ministério da Saúde, Agência Nacional 
de Vigilância Sanitária. - Brasília : Ministério da Saúde, 2006. i82 p. - (Série A. Normas e Manuais Técnicos) ISBN 85-334-1176-6

CARDOSO, Telma Abdalla de Oliveira. Biossegurança e qualidade dos serviços de saúde. Curitiba: interSaberes, 2016.

CAFURE, Vera Araujo; PATRIARCHA GRACIOLLI, Suelen Regina. Os resíduos de serviço de saúde e seus impactos ambientais: uma revisão bibliográfica. Interações (Campo Grande), Campo Grande, v. I6, n. 2, p. 301-314, Dec. 2015.

Availablefrom<http://www.scielo.br/scielo.php?script=sci_arttext\&pid=SI5187012201500020030I\&lng=en\&nrm=iso $>$. Acesso em 24 de setembro de 2019 . http://dx.doi.org/10.1590/151870122015206.

CAMPONOGARA, Silviamar; RAMOS, Flavia Regina Souza; KIRCHHOF, Ana Lucia Cardoso. Um olhar sobre a interface trabalho hospitalar e os problemas ambientais. Rev. Gaúcha Enferm. (Online), Porto Alegre, v. 30, n. 4, p. 724-731, Dec. 2009 . Availablefrom<http://www.scielo.br/scielo.php?script=sci_arttext \&pid=Sig83I4472009000400020\&lng=en\&nrm=iso $>$ Acesso em o8 de Março de 2020. https://doi.org/10.1590/Sig83-14472009000400020.

DELEVATI, Dionatan dos Santos et al . Desafios na gestão de resíduos de estabelecimentos de saúde públicos perante a RDC 222/18. Saúde debate, Rio de Janeiro, v. 43, n. $\quad$ spe3, p. 190-199, Dec. 2019. Available from $<$ http://www.scielo.br/scielo.php?script=sci_arttext\&pid=Soro3II042019000700190\&lng $=$ en $\& \mathrm{nrm}=$ iso $>$.

Acesso em 13 Maio de 2020. Epub Jan 13, 2020. https://doi.org/10.1590/oro3-11042019s314.

ERDTMANN, BernadetteKreutz. Gerenciamento dos resíduos de serviço de saúde: biossegurança e o controle das infecções hospitalares. Texto contexto - enferm., Florianópolis , v. 13, n. spe, p. 86-93, 2004. Availablefrom<http://www.scielo.br/scielo.php?script=sci_arttext\&pid=Soro4- 
07072004000500oro\&lng=en\&nrm=iso. Acesso em o8 de Março de 2020. https://doi.org/10.1590/So104-07072004000500010.

FERREIRA, João Alberto. Resíduos sólidos e lixo hospitalar: uma discussão ética. Cad. Saúde Pública, Rio de Janeiro, v. II, n. 2, p. 314-320, June 1995. Availablefrom<http://www.scielo.br/scielo.php?script=sci_arttext\&pid=Soro2311Xi995000200015\&lng=en\&nrm=iso.$\quad$ accesson $\quad 08 \quad$ Mar. 2020. https://doi.org/10.1590/Soro2-311X1995000200015.

LUZ, Francisco Xavier Ribeiro da; GUIMARAES, Cid. Resíduos hospitalares. Rev. Saúde Pública, São Paulo, v. 6, n. 4, p. 405-426, Dec. 1972 . Availablefrom<http://www.scielo.br/scielo.php?script=sci_arttext $\&$ pid=Soo3489101972000400009\&lng=en\& $n$ rm=iso $>$ accesson $\quad$ Mar. 2020. https://doi.org/10.1590/So034-89101972000400009.

Manual para normalização de trabalhos científicos e acadêmicos Faculdade Aldete Maria

Alves- $\quad$ Fama. 2020. Disponível em: «http://facfama.edu.br/uploads/files/novos_regulamentos/2019_trabalho_de_curso__o6_II.pdf >>. Acesso em janeiro de 2020.

MARCHIORATO, Alexa. Gestão hospitalar: serviços de higiene limpeza e manutenção.Curitiba: Intersaberes, 2017.

NASCIMENTO, Victor Fernandez et al . Evolução e desafios no gerenciamento dos resíduos sólidos urbanos no Brasil. Rev. Ambient. Água, Taubaté , v. Io, n. 4, p. 889-902, Dec. 2015 Availablefrom $<$ http://www.scielo.br/scielo.php?script=sci_arttext \&pid=SI98o993X2015000400889\&lng=en\&nrm=iso . accesson o8 Mar. 2020. https://doi.org/ro.4136/ambi-agua.1635. 
SANTOS, Ana Maria; SANTOS, Carlos Cesar dos. Resíduos sólidos hospitalares Quantificação estatística de resíduos e seu devido descarte no ambulatório do grupo B,i ed. São Paulo: Edição do autor, 2019.

SEVERINO, Antônio Joaquim. Metodologia do trabalho científico. 23. ed.rev. e atual. São Paulo: Cortez, 2007.

UEHARA, Sílvia Carla da Silva André; VEIGA, Tatiane Bonametti; TAKAYANAGUI, Angela Maria Magosso. Gerenciamento de resíduos de serviços de saúde em hospitais de Ribeirão Preto (SP), Brasil. Eng. Sanit. Ambient., Rio de Janeiro , v. 24, n. I, p. I21-130, Feb. 2019

Availablefrom<http://www.scielo.br/scielo.php?script=sci_arttext\&pid=SI4I34152201900oIool21\&lng=en\&nrm=iso>. accesson 22 Sept. 2019. Epub Aproi, 2019 . http://dx.doi.org/ro.159o/si413-41522019175893. 